\title{
HIGH RESOLUTION SAR IMAGING EMPLOYING GEOMETRIC FEATURES FOR EXTRACTING SEISMIC DAMAGE OF BUILDINGS
}

\author{
L. P. Cui ${ }^{1}$, X. Q. Wang ${ }^{1, *}$, A. X. Dou ${ }^{1}$, X. Ding ${ }^{1}$ \\ ${ }^{1}$ Institute of Earthquake Forecasting, China Earthquake Administration, Beijing 100036, China - (liping_cui, wangxiaoq517, \\ axdothy, dingxiang525)@163.com
}

KEY WORDS: SAR, Imaging Geometry Feature, Building, Seismic Damage Extraction

\begin{abstract}
:
Synthetic Aperture Radar (SAR) image is relatively easy to acquire but difficult for interpretation. This paper probes how to identify seismic damage of building using geometric features of SAR. The SAR imaging geometric features of buildings, such as the high intensity layover, bright line induced by double bounce backscattering and dark shadow is analysed, and show obvious differences texture features of homogeneity, similarity and entropy in combinatorial imaging geometric regions between the un-collapsed and collapsed buildings in airborne SAR images acquired in Yushu city damaged by 2010 Ms7.1 Yushu, Qinghai, China earthquake, which implicates a potential capability to discriminate collapsed and un-collapsed buildings from SAR image. Study also shows that the proportion of highlight (layover \& bright line) area (HA) is related to the seismic damage degree, thus a SAR image damage index (SARDI), which related to the ratio of HA to the building occupation are of building in a street block (SA), is proposed. While HA is identified through feature extraction with high-pass and low-pass filtering of SAR image in frequency domain. A partial region with 58 natural street blocks in the Yushu City are selected as study area. Then according to the above method, HA is extracted, SARDI is then calculated and further classified into 3 classes. The results show effective through validation check with seismic damage classes interpreted artificially from post-earthquake airborne high resolution optical image, which shows total classification accuracy $89.3 \%$, Kappa coefficient 0.79 and identical to the practical seismic damage distribution. The results are also compared and discussed with the building damage identified from SAR image available by other authors.
\end{abstract}

\section{INTRODUCTION}

High resolution optical remote sensing images have been widely used in earthquake disaster monitoring and assessment, but it is restricted in post-earthquake emergency application in the region of the cloudy, rainy or foggy weather, and can be used only in the daylight. Synthetic Aperture Radar (SAR), as an active remote sensing technology imaging in microwave band, can easily penetrate cloud, fog and rain, and is not restricted by weather factors and night-time. SAR, slant range imaging with high spatial resolution (meter even sub-meter), can obtain more information of 3D objects and be widely applied to emergency earthquake disaster information acquisition and evaluation (Dekker, 2011, Dell'Acqua et al., 2012, Dong et al., 2013, Gokon, et al., 2015). However, the range imaging makes geometry deformation of SAR image of building as foreshortening and top displacement, layerover and shadow, and usually there is a strong double bounce or even multiple backscattering. Even more, the highlight backscattering feature and complicated geometry in residential area with dense building distribution often cause great heterogeneity of SAR image. At the same time, the SAR system, as a coherent system, often cause significant speckle noise. All above features make the SAR image very difficult to be interpreted (Brett, 2013). Therefore, the development of seismic damage detection method suitable for SAR images has been a problem to be solved urgently.

At present, the visual interpretation of seismic damage of building from SAR images is still a widely applied method (Yang et al. 1999; Shao et al. 2008; Balz et al. 2010; Zhang et al. 2010). However, because of the special imaging mechanism and speckle noise for SAR image, there is still a subjective error of object identification even to the experienced interpreters. The change detection methods have been researched and applied to identify seismic damage of building by using the correlation between intensity information of SAR images acquired pre- and post-earthquake (Yonezawa et al., 1998, 2001; Matsuoka, 1999; Matsuoka et al, 2004a, 2004b; Marin, 2015), but these methods are usually used for low resolution SAR image and their results depend largely on the registration accuracy between the images. The speckle noise and other factors make registration between SAR images very difficult, resulting in misjudgement of seismic damage information. With the improvement of SAR image resolution, the geometric features of buildings on SAR images such as layerover, double bounce backscattering and shadow become more and more obvious, and are explored for building damage detection (Stilla, at al. 2005). Guida et al (2011, 2010a, $2010 \mathrm{~b})$ proposed to use the double bounce backscattering characteristics to extract the earthquake damage of the building. Brett (2013a, 2013b) proposed an automatic ridge detection method to extract the double reflection bright lines from preearthquake SAR image, then to extract seismic damage information according to the intensity change of bright lines to one in post-earthquake SAR image. Liu et al. (2013) analysed the seismic damage characteristics of buildings, roads and bridges in detail based on the imaging mechanism and the backscattering characteristics of SAR, the result provided a train of thought for finding suitable target detection and extraction methods. At present, the seismic damage of building is extracted mainly based on the double bounce backscattering feature of SAR image, while this method strongly depends on

\footnotetext{
* Corresponding author
} 
the existence of the bright lines and sometimes it might not be unreliable for the case that the bright lines are not obvious because of the influence of the surrounding environment or only back side of a building collapsed.

On the whole, although there are many methods for seismic damage detection of building, most of them are applicable to low and middle resolution SAR images, and cannot be fully adapted to high and very high resolution SAR images. The seismic damage identification based on the SAR imaging geometric features of the building is one of the important directions for future research. In this paper, the assessment of the seismic damage of buildings based on the geometric features of SAR imaging is briefly reviewed. The composition and features of the SAR imaging geometric parts of the building, such as high intensity layover, bright line induced by double bounce backscattering and dark shadow, are analysed. On this basis, as a case-study, airborne SAR images in Yushu City (Jiegu town) acquired immediately after 2010 Ms7.1 Yushu, Qinghai, China earthquake are selected. The texture features are analysed according to different imaging geometric areas for collapsed and un-collapsed buildings in SAR image. The relationship between the high intensity backscattering area and the building damage grade is analysed. A quantitative seismic damage index of SAR (SARDI) is proposed to describe the seismic damage grade in street block unit based on SAR image. Part of the Yushu City are selected for the damage detection. The SAR image are converted into HSV image by high-pass and low-pass filtering in frequency domain and further into RGB image. Then the highlight area are extracted by using the maximum likelihood classification. Then the SARDI index in each street block is calculated and classified into 3 seismic damage grades. The results are verified with seismic damage grade extracted visually from high resolution optical image for effectiveness.

\section{GEOMETRIC AND TEXTURE FEATURES OF} SEISMIC DAMAGE OF BUILDINGS IN SAR IMAGING

\subsection{Geometric Features of Seismic Damage of Buildings in SAR Imaging}

The building imaging is affected by layover, double bounce scattering and shadow etc. on the slant range SAR images. For a building model with uniform surface located in a flat ground, if the aircraft with SAR sensor flights parallel to the direction of building, then there will be three SAR imaging models according to the building height $(h)$, width $(w)$ and the incidence angle of SAR sensor, as shown in Figure 1.

In the condition of $h>w \cdot \tan (\theta)$ (Figure 1a), in the segment $\mathrm{A}^{\prime} \mathrm{B}$ ', the scattering from the roof $\mathrm{EF}$ is superimposed on the scattering from the wall $\mathrm{EG}$ and the ground $\mathrm{AB}$ into $\mathrm{a}+\mathrm{c}+\mathrm{d}$, causing a brighter layerover. In the $\mathrm{B}^{\prime} \mathrm{C}^{\prime}$ segment, the scattering of the ground $\mathrm{BC}$ is superimposed only on the scattering of the wall CG into a+c, causing the layerover of the second light. The sensor side of the wall and ground forms a dihedral corner reflector, the radar waves incident to the wall are reflected to the ground, and then reflected back to the radar. As the path length of the double bounce scattering radar wave is equal to the return path length of scattering wave to the corner point $\mathrm{C}$ (Franceschetti, 2003), All the components of the return waves are superimposed on each other, causing a very strong superposition of energy at the $\mathrm{C}$ point, forming the brightest double bounce scattering bright lines. In the C'D' segment, dark shadow are formed due to the absence of radar waves.

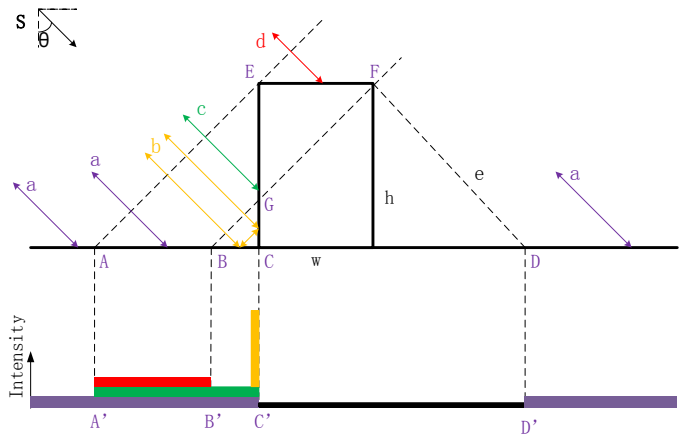

(a)

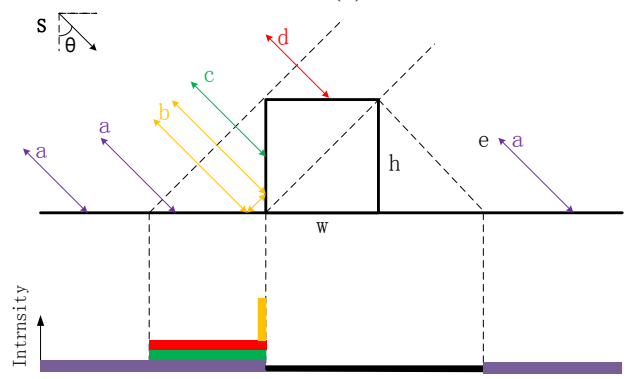

(b)

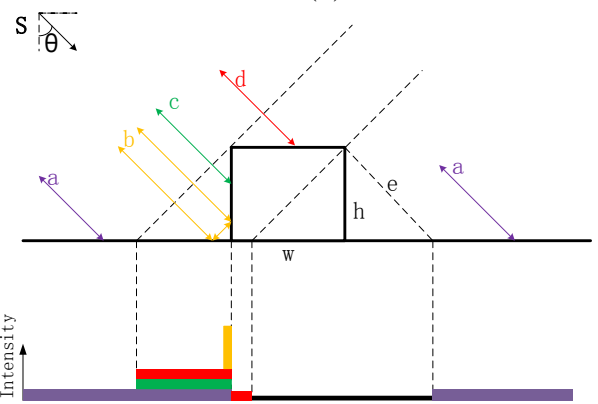

(c)

Figure 1. Scattering from a simple flat roof building model with width $w$ and heights $h$ : ground scattering a; double bounce b; scattering from vertical wall c; backscattering from roof $\mathrm{d}$; shadow area e. The gray values in the backscattering profiles correspond to the relative amplitudes. (a) $h>w \cdot \tan (\theta)$. (b) $h=$ $w \cdot \tan (\theta)$. (c) $h<w \cdot \tan (\theta)$. (Brunner, 2009, modified )

With the decrease of the height of the building $(h=w \cdot \tan (\theta)$, $h<w \bullet \tan (\theta))$, the position of backscattering wave $\mathrm{b}$ from roof $\mathrm{EF}$ and double bounce backscattering wave from EC and ground moves relatively back to side of the sensor, formed the imaging geometry structure diagram as Figure $1 \mathrm{~b}$ and $1 \mathrm{c}$ shows.

\subsection{Texture Features of Seismic Damage of Buildings in SAR Imaging}

Cui et al (2016) collected SAR images in shadow area and layerover area of 28 individual un-collapsed buildings, and images in collapsed area of 28 individual collapsed buildings from the post-earthquake airborne SAR image in Jiegu town which is seriously damaged by 2010 Yushu earthquake. The texture features of homogeneity, dissimilarity and entropy combined between shadow area \& layerover area for uncollapsed buildings or the collapsed area of collapsed buildings are compared respectively, as shown in Figure 2. The results show that the better reparability of collapsed building from uncollapsed building exist by using texture features in 
combinatorial geometric feature areas in SAR images, which provides a key basis to develop extraction methods of seismic damage of buildings based on high resolution SAR images.

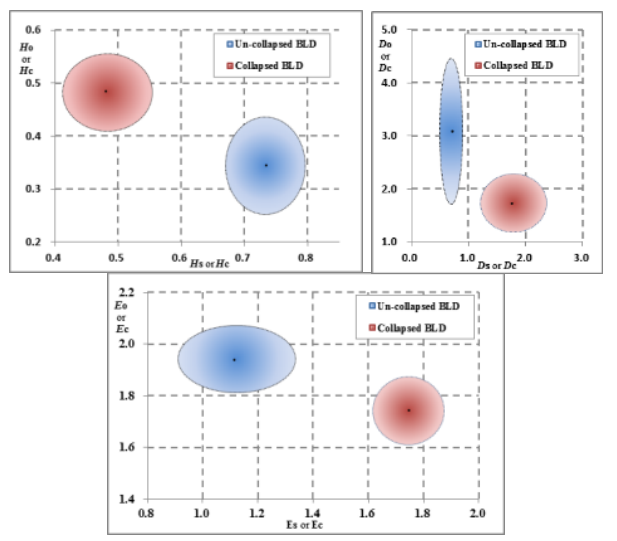

Figure 2. The mean and standard deviation of texture's in layover and shadowing areas of un-collapsed buildings, and the collapsed area of buildings. $H, D, E$ refers to homogeneity, dissimilarity and entropy separately; o, s refers to layer-over \& shadow areas separately for un-collapsed building; c refers to collapsed area of collapsed building (Cui et al, 2016) .

\section{EXTRACTION TEST OF SEISMIC DAMAGE OF BUILDING FROM SAR IMAGE}

According to the above analysis, the collapsed and un-collapsed buildings can be well discriminated according to the geometric features on SAR imaging, therefore, the seismic damage of buildings through SAR imaging geometric feature would be identified by the assistance of vector data of buildings prepared before an earthquake occurs, or extracted immediately from preearthquake high resolution optical images in post-earthquake emergency stage. While it may be difficult to identify building damage by the above methods in the case of lack of building vector data before earthquakes. Another corollary according to the above analysis is that, because of the layerover and double bounce scattering, there exist a certain ratio of high bright area to the street block area in SAR images, and such ratio is related to the proportion of building collapse in the block. Therefore, in the case of only post-earthquake SAR images acquired, such ratio is useful to assess quantitatively the distribution of seismic damage in street blocks.

\subsection{Research Area and SAR Data Pre-processing}

To study and verify the method of seismic damage extraction from SAR image, the Yushu City is chosen as the research area.

On April 14, 2010, the Ms7.1 earthquake occurred in Yushu County (96.6E, 33.2N), Qinghai province, China. The depth of the earthquake was 14 kilometres. The maximum seismic intensity is IX. The catastrophe earthquake caused 2220 death, 70 missing and large number of building collapsed, especially in the Yushu City (Jiegu town). The main building structures in the town are adobe-wooden (more than 70\%), brick-wooden and masonry (20\%) and frame (10\%). In many street blocks, almost all the adobe-wooden and brick-wooden houses, some masonry houses and few of frame house were collapsed or seriously damaged.
The high resolution $(0.5 \mathrm{~m})$ airborne X-band SAR intensity image (Figure 3) acquired in Jiegu town on April 17, 2010 by National Administration of Surveying, Mapping and Geoinformation, China (NASG). The direction of the aircraft is east-west, the radar beam from south to north. The SAR image has been pre-processed with spatial registration and speckle denoising filtered by Gamma filtering method $(5 \times 5$ in size of window) . Figure 4-6 shows the features of SAR images of buildings with different damage grade.

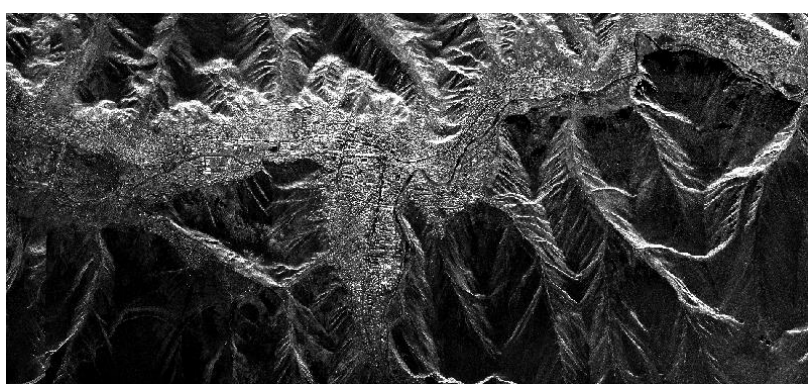

Figure 3. Airborne SAR image in Yushu City acquired (by NASG, China) on April 17, 2010, immediately after Ms7.1 earthquake occurred in Yushu, Qinghai, China on April 14. The image has been pre-processed with spatial registration and speckle denoising filtering.

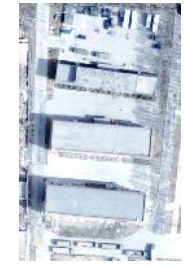

(a)

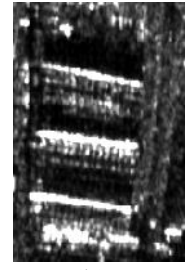

(b)
Figure 4. Post-earthquake airborne optical image (a) and SAR image (b) of un-collapsed building.

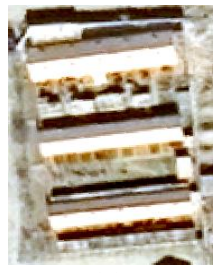

(a)

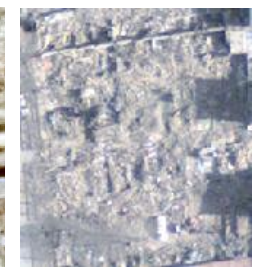

(b)

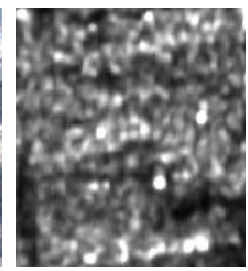

(c)
Figure 5. Pre-earthquake QuickBird image (a); post-earthquake airborne optical (b) and SAR (c) images of collapsed building. (a)

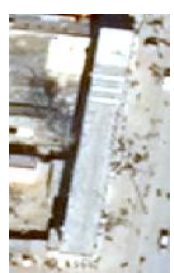

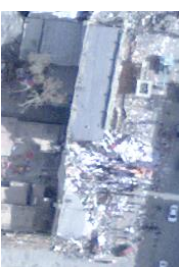

(b)

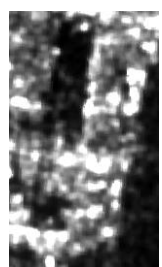

(c)
Figure 6. Pre-earthquake QuickBird image (a); post-earthquake airborne optical (b) and SAR (c) images of partial-collapsed building. 


\subsection{The Seismic Damage Index of Building based on Highlighting Area of SAR Image}

Based on the imaging geometric features of double bounce scattering bright lines and the part of the bright layover area (hereinafter referred to as the highlight area) on the SAR image, a quantitative seismic damage assessment model is proposed. First the SAR Damage Index (SARDI) is introduced to quantify the seismic damage distribution of the building as following:

$$
D_{\mathrm{SAR}}=1-\frac{S_{\mathrm{HL}}}{S_{\mathrm{SB}}}
$$

Where $\quad D_{\mathrm{SAR}}=$ average seismic damage index based on SAR image (SARDI) in a street block

$S_{\mathrm{HL}}=$ highlight area of the street block on SAR image

$S_{\mathrm{SB}}=$ total area occupied by the buildings within a street block

\subsection{The Extraction of Highlighting Area from SAR Image}

Due to the influence of the direction, area and height of a building, the shape and material of its surface (roof and side), and the intensity of highlighting are expected to change considerably in different building, thus it is not available to extract the highlight area with the simple threshold from the whole SAR image. Study shows that the feature in highlight area is different in the frequency domain. So the SAR image in spatial domain is filtered in frequency domain (with a convolution kernel size 11) and transformed into the high pass filtering images (HP) and low pass filtering image (LP). By setting the LP to tone (Hue), HP to the intensity or colour value (Value), and a constant (0.5) to saturation value (Saturation), an image is composed in HSV colour space. The image is further transformed into the RGB colour space, so that the original gray scale SAR image (Figure 7a) is transformed into a colour image representing a multi-feature combination (Figure 7b).

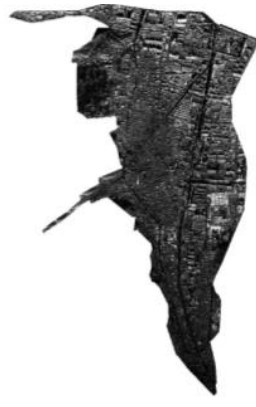

(a)

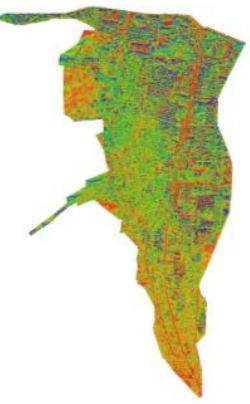

(b)

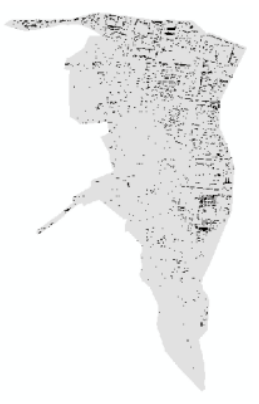

(c)
Figure 7. SAR image (a) and its synthetic colour image by features in frequency domain (b), extracted highlighted area (c).

Such transformation preserves the details of the radar image and improves the effectiveness of the SAR image interpretation.

The highlight area and other area are selected as 2 class regions. Then some training samples are selected and maximum likelihood classification is applied to get the highlight area distribution map of the study area (Figure 7c).
3.4 The Results and Verification of the Quantitative Assessment of the Seismic Damage of Building based on the SAR Image

The highlighting area of each street block in Figure $7 \mathrm{c}$ is calculated and then SARDI is determined according to the equation (1). The result, compared with the seismic damage index RSDI or $D_{\text {RS }}$ (Wang, et al, 2013) which is obtained from the high resolution airborne optical image, is shown in Figure 8. It shows that SARDI is related to RSDI as follows:

$$
D_{\mathrm{SAR}}=1-0.898 \mathrm{e}^{-4.606 D_{\mathrm{RS}}}
$$

The correlation coefficient between SARDI and RSDI is 0.82 .

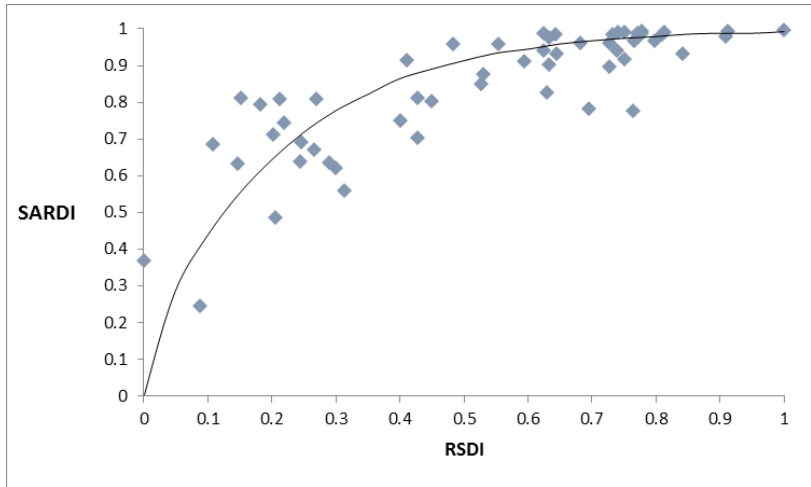

Figure 8. Correlation analysis between the SAR seismic damage index SARDI and the optical remote sensing seismic damage index RSDI.

Next, in order to get the spatial distribution of seismic damage and verify the effectiveness of the result, The seismic damage grade is divided into 3 categories according to RSDI value: $\mathrm{C}$ : $D_{\mathrm{RS}}=0-0.1 ; \mathrm{C} 2: D_{\mathrm{RS}}=0.1-0.45$ and C3: $D_{\mathrm{RS}}=0.45-1.0$. The classification results of the 3 category are shown in figure $9 \mathrm{a}$. According to equation (2), the seismic damage grade is also divided into 3 categories according to SARDI value: $C 1$ : $D$ SAR $=0-0.43 ; \mathrm{C} 2: D_{\mathrm{SAR}}=0.43-0.89$ and C $3: D_{\mathrm{SAR}}=0.89-1.0$. The classification results of the 3 category are shown in figure $9 \mathrm{~b}$. It is shown that the most seriously damage areas are located in the west and south of the study area.

If the building damage classification based on the visual interpretation of high resolution optical images are taken as the real results, then the results classified based on SAR images can be verified for effectiveness. The confusion matrix is shown in Table 1. The results show that the overall classification accuracy of seismic damage of building from the SAR image is $89.3 \%$, and the Kappa coefficient is about 0.79 , which implicate that the classification results based on automatic extraction of seismic damage of building from SAR image in the paper are basically consistent with the results by visual interpretation from high resolution airborne optical images.

\begin{tabular}{lllll}
\hline \multirow{2}{*}{$\begin{array}{l}\text { Street block } \\
\text { number }\end{array}$} & \multicolumn{4}{c}{ Classification by SARDI } \\
\cline { 2 - 5 } & & $\mathrm{C} 1$ & $\mathrm{C} 2$ & $\mathrm{C} 3$ \\
\hline \multirow{2}{*}{$\begin{array}{l}\text { Classification } \\
\text { by RSDI }\end{array}$} & $\mathrm{C} 1$ & 2 & 0 & 0 \\
\cline { 2 - 5 } & $\mathrm{C} 2$ & 0 & 19 & 1 \\
\cline { 2 - 5 } & $\mathrm{C} 3$ & 0 & 5 & 29 \\
\hline
\end{tabular}

Table 1. The confusion matrix table for seismic damage classification from airborne SAR image 


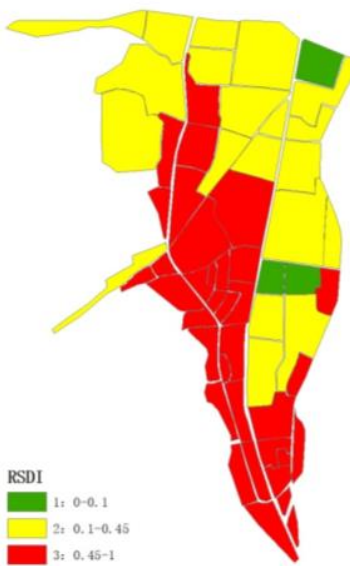

(a)

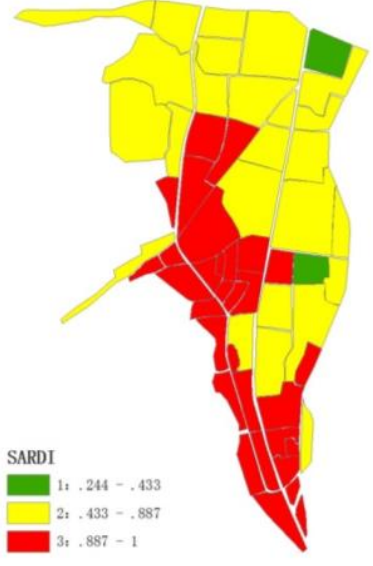

(b)
Figure 9. The classification maps of the seismic damage based on RSDI by visual interpretation from the airborne high resolution optical image (a) (Wang et al, 2013) and SARDI by automatic extracted from airborne SAR image in this paper (b) .

\section{CONCLUSIONS}

This paper analysed the imaging geometry models and features of buildings and their damages due to earthquake on airborne High resolution SAR image, the results were shown that the relative completed and continuous imaging geometry features including layerover, double bounce scattering (highlight line) and shadow for the un-collapsed buildings. Such completeness and continuity will be destroyed for collapsed or partially collapsed buildings. As the increase of damage severity, the integrity and continuity will decline. The texture features such as homogeneity, similarity, entropy in each kind of imaging geometry region are corresponding to the damage grade (the collapsed or the un-collapsed) of building and thus it is potentially useful for the development of identification of seismic damage of buildings. It is shown that the spatial occurrence rate of the highlight area including the layerover and double bounce scattering regions can be used as a good indicator for identification of the seismic damage. On this basis, the quantitative seismic damage index based on SAR image (SARDI) was proposed to associate with the proportion of the highlight area to the occupation area of buildings in a street block. In order to avoid the defect of single threshold used to identify the highlight area from SAR image, feature extraction method was proposed by using high pass and low pass filtering in frequency domain. To validate the method and index, a postearthquake airborne high resolution SAR image in the Jiegu town (Yushu City), the seriously damaged area caused by 2010 Ms7.1 Yushu earthquake, was chosen to extract the highlight regional distribution by using frequency method of high pass and low pass filtering. The spatial distribution of SARDI was established and verified quantitatively with seismic damage index of building (RSDI) visually interpreted from postearthquake airborne high resolution optical image. The overall classification accuracy and Kappa coefficient test shown good consistency of SARDI to RSDI, which verify the effectiveness of the method proposed in the paper.

Other methods for building damage identification based on SAR have also been applied in the Yushu City. Guo et al. (2010) extracted the spatial distribution of building collapse (in pixel level) with percentage of collapsed buildings $55 \%$ from
Radarsat-2 polarimetric SAR data by using the $\mathrm{H}-\alpha-\rho$ method. Wang et al. (2011) estimated the building damage from COSMO-SkyMed image by using fractal analysing methods. Chen et al. (2011) estimated the building damages (in grid size $100 \mathrm{~m}$ ) with average damage rate $55 \%$ based on the phase coherence between pre- and post-earthquake ALOS SAR intensity images. Zhao et al. (2013) estimate the damage level at the block scale by using the method of combining polarimetric and spatial texture of the airborne polarimetric SAR data imagery. Zhai et al. (2016) proposed a method combining polarization orientation angle compensation and its relative contribution change rate to extract building damage information by using a single post-earthquake PolSAR image with overall accuracy $79 \%$. All the above methods shown capability to extract building damage from SAR image. But the difference exists. Some results (Guo et al., 2011; Zhao et al., 2013) have obvious miss identification of building damage, especially in the northeast part of the city. Comparison in detail and limited in the area of the current paper (Figure 9) show that the building damage distribution by using the methods of phase coherence (Chen et al , 2011), and imaging geometric features (Zhai et al, 2016; the current paper) are more closer to the practice shown in Figure 9a. It is also the effectiveness of the method proposed in the paper.

\section{ACKNOWLEDGEMENTS}

The authors would like to thank the anonymous reviewers. The airborne SAR image was provided by NASG. The research was supported by key research and development project of the Ministry of Science and Technology (2017YFB0504104).

\section{REFERENCES}

Balz T., Liao M., 2010. Building-damage detection using postseismic high-resolution SAR satellite data. International Journal of Remote Sensing, 31(13), pp. 3369-3391.

Brett P.T.B., 2013a. Urban damage detection in high resolution amplitude images. University of Surrey, Surrey Space Centre.

Brett P.T.B., 2013b. Urban damage detection in high resolution amplitude images. University of Surrey, Surrey Space Centre.

Brett P.T.B., Guida R., 2013. Earthquake damage detection in urban areas using curvilinear features. Geoscience \& Remote Sensing IEEE Transactions, 51(9), pp. 4877-4884.

Brunner, D., 2009. Advanced methods for building information extraction from very high resolution SAR data to support emergency response. University of Trento.

Chen L.Z., Shen X.H., Hong S.Y., et al., 2011. Estimation of the building damages in Yushu earthquake based on ALOS SAR data. International Symposium on Multispectral Image Processing \& Pattern Recognition, Proceedings of SPIE International Society for Optics and Photonics. 8006(1), pp. 420-430.

Cui L. P., Wang X. Q., Dou A. X., Jin D. J., 2016. Building damage analysis based on high resolution synthetic aperture radar imaging geometry. ACTA Seismological Sinica, 38(2), pp. 272-282 (in Chinese with English abstract).

Dekker R.J., 2011. High-resolution radar damage assessment after the earthquake in Haiti on 12 January 2010. Selected 
Topics in Applied Earth Observations \& Remote Sensing IEEE Journal, 4(4), pp. 960-970.

Dell'Acqua F., Gamba P., 2012. Remote sensing and earthquake damage assessment: experiences, limits, and perspectives. Proceedings of the IEEE, 100, pp. 2876-2890.

Dong L., Shan J., 2013. A comprehensive review of earthquakeinduced building damage detection with remote sensing techniques. ISPRS Journal of Photogrammetry \& Remote Sensing, 84(7), pp. 85-99.

Gokon H., Post J., Stein E., et al., 2015. A method for detecting buildings destroyed by the 2011 Tohoku earthquake and tsunami using multitemporal TerraSAR-X data. Geoscience \& Remote Sensing Letters IEEE, 12(6), pp. 1277-1281.

Guida R., Iodice A., Riccio D., 2010a. Fast change detection algorithm for single post-earthquake SAR images of urban areas, RiNEm. Beneveneto, Italy.

Guida R., Iodice A., Riccio D., 2010b. Monitoring of collapsed build-up areas with high resolution SAR images. Geoscience and Remote Sensing Symposium (IGARSS), 2010 IEEE International. Honolulu, HI.

Guida R., Iodice A., Riccio D., 2011. An application of the deterministic feature extraction approach to COSMO-SkyMed data. European Conference on Synthetic Aperture Radar, 2011 92, pp. 1-4.

Guo H.D., Wang X.Y., Li X.W., et al., 2010. Yushu earthquake synergic analysis using multimodal SAR datasets. Chinese Science Bulletin, 55(31), pp. 3499-3503.

Liu J.Y., Zhang J.F., Liu G.L., 2013. An analysis of earthquake damage information based on imaging mechanism of the high resolution SAR image. Remote Sensing for Land and Resources, 25(3), pp. 61-65 (in Chinese with English abstract).

Marin C., Bovolo F., Bruzzone L., 2015. Building change detection in multitemporal very high resolution SAR images. Geoscience \& Remote Sensing IEEE Transactions on, 53(5), pp. 2664-2682.

Matsuoka M., Yamazaki F., 1999. Characteristics of satellite images of damaged areas due to the 1995 Kobe earthquake. Proc. of 2nd Conference on the Applications of Remote Sensing and GIS for Disaster Management. The George Washington University.

Matsuoka M., Yamazaki F., 2004a. Use of satellite SAR intensity imagery for detecting building areas damaged due to earthquakes. Earthquake Spectra, 20(3), pp. 975-994.
Matsuoka M., Yamazaki F., 2004b. Damage detection for the 2003 Algeria earthquake using SAR intensity images. Processing of 1st Asia Conference on Earthquake Engineering.

Shao Y., Gong H.Z., Wang S.A., Zhang F.L., Tian W., 2008. Multi-source SAR remote sensing data for rapid response to Wenchuan earthquake damage assessment. Journal of Remote Sensing, 12(6), pp. 865-870 (in Chinese with English abstract).

Stilla U., Soergel U., Thoennessen U., et al., 2005. Potential and limit for Reconstruction of buildings from high resolution SAR data of urban areas.

Wang X.Q., Jin D.J., Dou A.X., 2011. Study on the fractal analysis of SAR images and its application to the extraction of seismic damage of 2010 Yushu, China Ms=7.1 earthquake. Geoscience and Remote Sensing Symposium. IEEE International, pp. 1981-1984.

Wang X.Q., Dou A.X., Sun G.Q., Ding X., Wang L., Yuan X.X., 2013. Intensity assessment of the 2010 Yushu Ms7.1 earthquake based on synthetic seismic damage index. Earthquake, 33(2), pp. 1-10.

Wei Z., Huang C.L., 2016. Fast building damage mapping using a single post-earthquake PolSAR image: a case study of the 2010 Yushu earthquake. Earth Planets \& Space, 68(1), pp. 86.

Yang Z., Ren F., 1999. Quick determination of epicentral region using airborne earthquake disastrous SAR image characters. Seismology and Geology, 21(4), pp. 452-458 (in Chinese with English abstract).

Yonezawa C., Shoji T., 1998. Detection of damaged built-up areas by the 1995 Hyogoken-nanbu earthquake using ERS1/SAR intensity images. Journal of the Japan Society of Photogrammetry, 37(4), pp. 57-61.

Yonezawa C., Takeuchi S., 2001. Decorrelation of SAR data by urban damages caused by the 1995 Hyogoken-nanbu earthquake. International Journal of Remote Sensing, 22(8), pp. 1585-1600.

Zhang J.X., Huang G.M., Liu J.P., 2010. SAR remote sensing monitoring of the Yushu Earthquake disaster situation and the information service system. Journal of Remote Sensing, 5(5), pp. 1038-1052.

Zhao L.L., Yang J., Li P.X., et al., 2013. Damage assessment in urban areas using post-earthquake airborne PolSAR imagery. International Journal of Remote Sensing, 34(24), pp. 89528966. 